Section Editor

John J. Millichap, MD MRCP

Etienne Laverse, MRCP Alex Henderson, PhD

Correspondence to

Dr. Samaraweera:

amal.samaraweera@doctors.org.uk

Pearls \& Oy-sters:

Vascular EDS presenting with

\title{
acute proptosis
}

\section{Always revisit the history}

\section{PEARLS}

- Joint hypermobility and skin hyperelasticity are unusual features in vascular Ehlers-Danlos syndrome (vEDS).

- $v E D S$ is an autosomal dominant disorder caused by mutations in the COL3A1 gene on chromosome 2.

- Spontaneous carotid-cavernous fistulae (CCF) can occur in the context of vEDS.

- Women need to be counseled about the increased complication rates during pregnancy and delivery.

\section{OY-STERS}

- The clinical assessment and history should be revisited in order not to miss subtle symptoms such as bruising and thin skin with a visible venous pattern, which may suggest a diagnosis of vEDS.

- A clear obstetric history can aid in formulating a diagnosis.

- Angiography in patients with vEDS is associated with high morbidity rates secondary to the increased risk of carotid dissection, arterial perforation, and hematoma.

CASE REPORT A 40-year-old woman presented to the emergency department in December 2010 with acute proptosis of the right eye, periorbital bruising, headache, and vomiting. On the day of presentation, she experienced a "whooshing noise" in her head alongside the severe headache.

Her medical history included previous unsuccessful attempts at in vitro fertilization and fibroidectomy. Her mother had died at age 36 years of primary biliary cirrhosis. Initial examination revealed right eye proptosis and bruising, a complex ophthalmoplegia, conjunctival injection, and an orbital bruit over the right temple and periorbital region (figure). There was a sluggish pupillary response to light in the right eye. Visual acuity in the right eye was 20/80 and $20 / 20$ in the left. Funduscopy at presentation was reported as normal, as were the general medical and peripheral neurologic examinations.

A complete blood count, as well as thyroid function tests and clotting screen, were within normal parameters. MRI revealed a right CCF that was thought to be spontaneous in onset (figure). A retrobulbar hemorrhage was incised and drained by the emergency ophthalmology service on the night of her admission.

During her subsequent inpatient stay, she underwent transarterial and transvenous embolization procedures. A subsequent CT angiogram demonstrated a residual fistula with drainage through the right inferior ophthalmic vein. The proptosis and restriction of eye movements persisted. There was a repeated attempt at embolization using a transvenous approach via the facial vein a few months later, because there had been complications with arterial dissection in the initial procedure.

The underlying cause of the spontaneous CCF was later elucidated after the history was revisited in its entirety. There was no history at the time of joint hypermobility, elastic-like skin, or bleeding. However, on retaking the history, she reported that each time her dog jumped on her with its paws, she bruised easily, which she had noticed for a few years. Furthermore, previous excision of uterine fibroids had led to significant postoperative hemorrhage. We therefore suspected a collagen disorder or a phenotype of EDS that did not always present with classic joint hypermobility or hyperelasticity of the skin, i.e., vascular EDS. Subsequent genetic analysis revealed a COL3A1 mutation (c.1347+1G $>A$ ) confirming the diagnosis.

Five years later, in 2015, our patient continues to have ocular problems with diplopia and an inability to abduct the right eye. She has had recurrent corneal abrasions due to residual incomplete right eye closure causing xerophthalmia. Coeliac axis and iliac and renal artery aneurysms have been detected on systemic vascular screening. She is currently on losartan and celiprolol. Her father tested negative for the mutation, but it was thought that her mother may have been affected by the disease as she had facies

From the Department of Neurology (A.P.R.S., E.L.), Royal Victoria Infirmary, Newcastle upon Tyne NHS Foundation Trust; and Institute of Genetic Medicine (A.H.), International Centre for Life, Times Square, Newcastle upon Tyne, UK.

Go to Neurology.org for full disclosures. Funding information and disclosures deemed relevant by the authors, if any, are provided at the end of the article. 

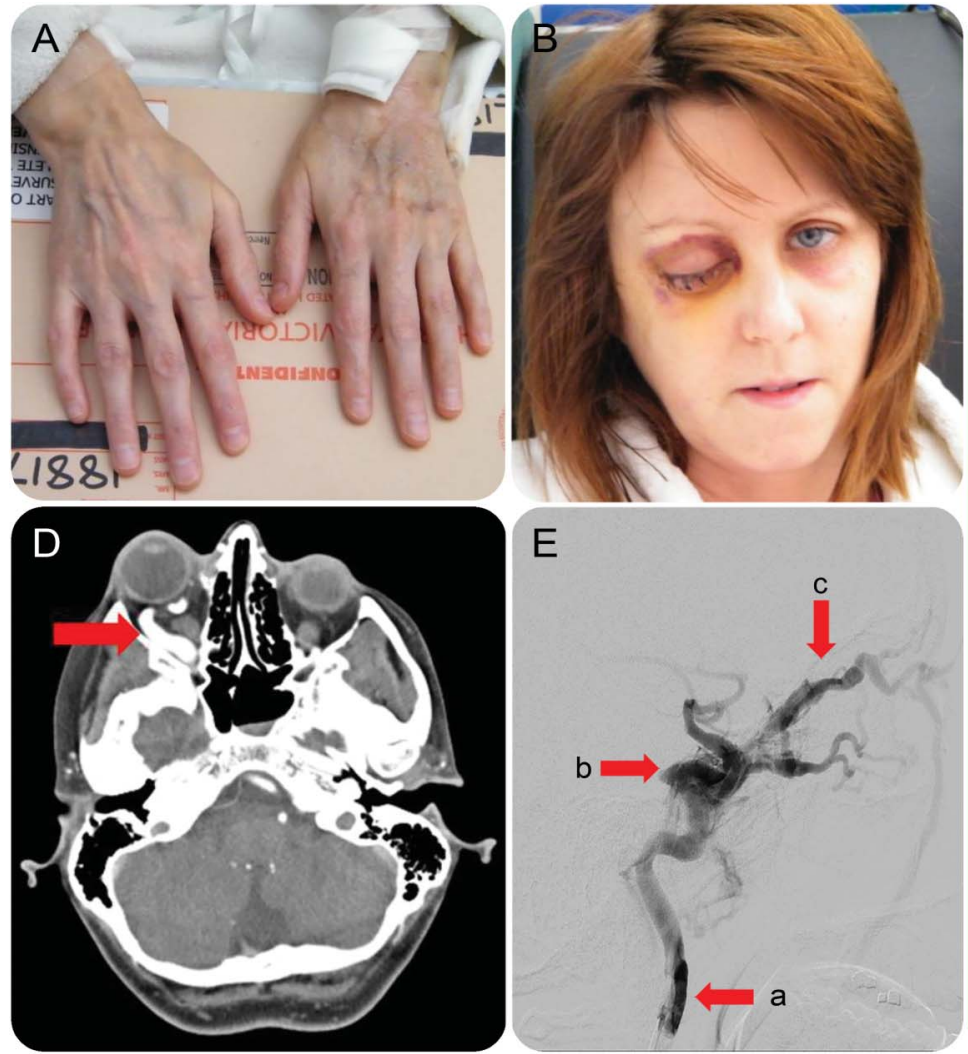

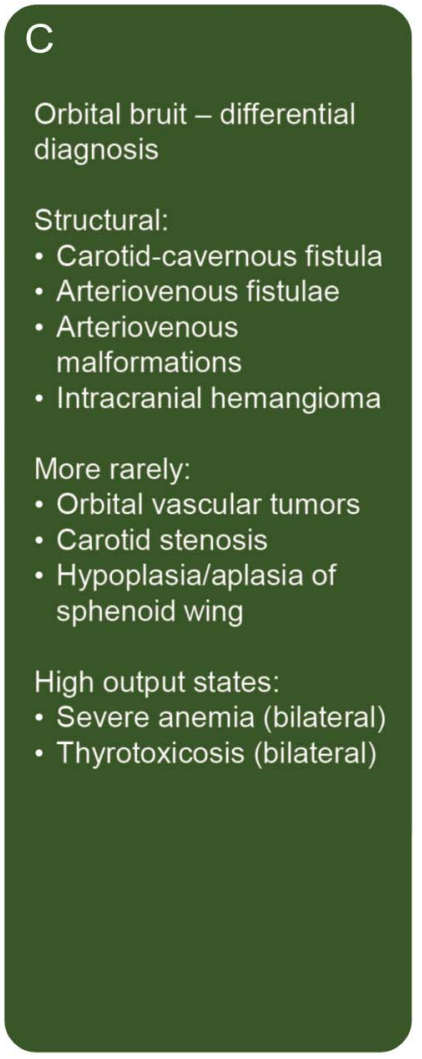

(A) A feature of vascular Ehlers-Danlos syndrome is thin translucent skin with a prominent venous pattern. (B) Periorbital bruising approximately 10 days after presentation. (C) Differential diagnosis of the orbital bruit. (D) Axial CT scan showing a dilated right superior ophthalmic vein (arrow) and (E) catheter angiography demonstrating (a) internal carotid artery showing catheter and IV contrast, (b) cavernous sinus with a vein filled with contrast and indicating that a fistula is present, and (c) congested superior ophthalmic vein, which usually drains into the cavernous sinus, but has reverse flow because of arterial back pressure.

compatible with EDS, clubbed feet, and a uterine rupture during childbirth with our patient.

DISCUSSION vEDS is rare in comparison to the more common presentation of the "classic" phenotype of EDS with hypermobile joints and skin hyperextensibility, which is more often taught. In the vascular subtype, the skin can be thin and transparent with a prominent venous pattern. ${ }^{1}$ It has an estimated prevalence of 1 per $150,000^{2}$ and can present with life-threatening features such as arterial dissections, spontaneous arterial ruptures, uterine ruptures, and gastrointestinal perforations, usually from early adulthood. ${ }^{2,3}$ In a retrospective study, the median age at diagnosis was 29 years. ${ }^{1}$ Median survival is 40 to 50 years, with the first complication usually seen by age $20 .^{3}$ It is therefore a crucial diagnosis not to miss. The vascular subtype has a poor prognosis because of the susceptibility to rupture arteries and hollow organs at a relatively young age. ${ }^{1}$

vEDS is caused by autosomal dominant (de novo mutations occur less frequently) mutations in the
COL3A1 gene on chromosome 2, a gene involved in coding the pro- $\alpha_{1}$ chain, 3 of which form type III procollagen, which itself has a triple helix structure. Reduced synthesis leads to structural defects within procollagen and subsequently type III collagen fibrils. ${ }^{2}$ This along with other fibrillary collagens is essential in providing structure and strength to the extracellular matrix of numerous tissues in the body including skin, blood vessel walls, and bowel. ${ }^{1}$ Most of the variants are missense substitutions affecting the amino acid glycine, causing incorrect linking of the $\alpha_{1}$ chains within the triple helical structure. ${ }^{2}$

The classification of EDS (Villefranche classification) comprises 6 subtypes, based on the typical clinical features seen in each, with the vascular subtype being one of them. ${ }^{4}$

The potential lack of classic signs and symptoms of hypermobility with vEDS is a principal reason leading to delayed diagnosis and misdiagnosis. It is therefore essential to revisit the patient's history to elicit overlooked symptoms and signs such as thin translucent skin, easy bruising (such as in our patient), joint laxity particularly prominent in the 
hands, congenital clubfoot or congenital hip dislocation and facial features such as a thin nose, small chin, and lack of subcutaneous adipose tissue causing hollow cheeks and prominent eyes. ${ }^{1,5}$

With that said, sometimes facial and skin changes may be subtle or absent. ${ }^{1}$ Excessive bruising is the most common sign and often leads to the initial presentation. ${ }^{1}$ A history of arterial or uterine rupture and sudden death in a relative is also key. Nonetheless, a formal diagnosis of vEDS requires evidence of a pathogenic mutation within the COL $3 A 1$ gene. $^{2}$

CCF are abnormal arteriovenous connections between the internal or external carotid arteries and the cavernous sinus. ${ }^{6}$ Classification of a CCF is based on the Barrow classification, dividing them into direct or indirect shunts. ${ }^{7}$ Type A describes a direct connection between the internal carotid artery and the cavernous sinus and types B, C, and D describing indirect shunts between the dural meningeal branches of the internal or external carotid arteries and the cavernous sinus. ${ }^{6,8}$ Spontaneous CCF in association with vEDS has been reported. In a retrospective study of vEDS cases, a CCF was detected in 6 of 100 patients. ${ }^{1}$ In one case series, $3 \%$ of cases $(6 / 202)$ had a CCF. ${ }^{5}$ However, most cases in the general population are secondary to trauma and subsequent damage to the internal carotid artery wall in the cavernous sinus. ${ }^{5}$

A spontaneous type A CCF can result from rupture of an aneurysm in the cavernous portion of the internal carotid artery, in addition to vEDS caused by a weak arterial wall. ${ }^{6}$ The onset of signs and symptoms is usually acute and severe, presenting with pulsatile proptosis, engorged episcleral veins, and an orbital bruit. ${ }^{6,8}$

Subsequent increased intraorbital pressure can cause enlargement of the extraocular muscles to the affected eye and ophthalmoplegia, with the abducens nerve most commonly affected in up to $85 \%$ of direct CCF. Venous stasis leads to enlargement of the retinal veins, retinal hemorrhage, and increased orbital pressure, which can cause papilledema. ${ }^{6} \mathrm{CT}$ and magnetic resonance angiography are useful investigative tools that demonstrate the CCF. Digital angiography is the key investigation that can reveal both the anatomy of the fistulae and the extent of collateral flow features that are important in treatment considerations. ${ }^{6,9}$

Important prophylactic measures to undertake after vEDS has been diagnosed include avoiding invasive vascular procedures, such as catheterization, because of the risk of vascular ruptures. ${ }^{1}$ Angiography in patients with vEDS has been associated with morbidity rates of $36 \%$ to $67 \%$ secondary to the increased risk of carotid dissection, arterial perforation, and hematoma. ${ }^{9}$

A prospective randomized trial showed that the cardioselective $\beta$-blocker, celiprolol, a long-acting $\beta_{1}$-adrenoceptor antagonist with partial $\beta_{2}$-adrenoceptor agonist properties, decreased the incidence of vascular complications by 3 -fold in patients with vEDS. ${ }^{1,3}$ Anticoagulant therapy should also be prescribed with caution as fatal bleeding may result. ${ }^{5}$

Thus, the occurrence of neurologic symptoms and signs in an individual with a history suggestive of vEDS should prompt the physician to investigate for the genetic abnormality and systemic vascular pathology, by noninvasive methods, so that appropriate prophylactic measures can be adopted to reduce the likelihood of lifethreatening complications.

\section{AUTHOR CONTRIBUTIONS}

A.P.R. Samaraweera was involved in the care of the patient, contributed to drafting/revising the manuscript, and critical revision for important intellectual content. E. Laverse contributed to drafting/ revising the manuscript and critical revision for important intellectual content. A. Henderson was involved in the care of the patient, contributed to writing the manuscript, interpretation of genetic data, and critical revision for important intellectual content.

\section{STUDY FUNDING}

No targeted funding reported.

\section{DISCLOSURE}

A. Samaraweera reports sponsorship for travel and meeting/conference attendance by Biogen Idec, Teva, and Novartis. E. Laverse and A. Henderson report no disclosures relevant to the manuscript. Go to Neurology.org for full disclosures.

\section{REFERENCES}

1. De Paepe A, Malfait F. The Ehlers-Danlos syndrome, a disorder with many faces. Clin Genet 2012;82:1-11.

2. Frank M, Albuisson J, Ranque B, et al. The type of variants at the COL3A1 gene associates with the phenotype and severity of vascular Ehlers-Danlos syndrome. Eur J Hum Genet 2015;23:1657-1664.

3. Ong KT, Perdu J, De Backer J, et al. Effect of celiprolol on prevention of cardiovascular events in vascular EhlersDanlos syndrome: a prospective randomised, open, blinded-endpoints trial. Lancet 2010;376:1476-1484.

4. Beighton P, De Paepe A, Steinmann B, Tsipouras P, Wenstrup RJ. Ehlers-Danlos syndromes: revised nosology, Villefranche, 1997. Am J Med Genet 1998;77:31-37.

5. North KN, Whiteman DAH, Pepin MG, Byers PH. Cerebrovascular complications in Ehlers-Danlos syndrome type IV. Ann Neurol 1995;38:960-964.

6. Tytle TL, Punukollu PK. Carotid cavernous fistula. Semin Cerebrovasc Dis Stroke 2001;1:83-108.

7. Barrow DL, Spector RH, Braun IF, Landman JA, Tindall SC, Tindall GT. Classification and treatment of spontaneous carotid-cavernous sinus fistulas. J Neurosurg 1985;62:248-256.

8. Bone I, Hadley DM. Syndromes of the orbital fissure, cavernous sinus, cerebellopontine angle and skull base. J Neurol Neurosurg Psychiatry 2005;76(suppl 3):29-38.

9. Ruff IM, Strozyk D, Rahman C, Szeder V, Pile-Spellman J, Marshall RS. Clinical Reasoning: a 21-year-old woman with right eye swelling and bruising. Neurology 2010;75:2039-2044. 


\section{Neurology}

\section{Pearls \& Oy-sters: Vascular EDS presenting with acute proptosis: Always revisit the history}

Amal P.R. Samaraweera, Etienne Laverse and Alex Henderson

Neurology 2016;87;e36-e38

DOI 10.1212/WNL.0000000000002893

This information is current as of July 25, 2016

\section{Updated Information \& Services}

References

Subspecialty Collections

Permissions \& Licensing

Reprints including high resolution figures, can be found at: http://n.neurology.org/content/87/4/e36.full

This article cites 9 articles, 1 of which you can access for free at: http://n.neurology.org/content/87/4/e36.full\#ref-list-1

This article, along with others on similar topics, appears in the following collection(s):

Clinical neurology examination

http://n.neurology.org/cgi/collection/clinical_neurology_examination Clinical neurology history

http://n.neurology.org/cgi/collection/clinical_neurology_history Orbit

http://n.neurology.org/cgi/collection/orbit

Information about reproducing this article in parts (figures,tables) or in its entirety can be found online at:

http://www.neurology.org/about/about_the_journal\#permissions

Information about ordering reprints can be found online:

http://n.neurology.org/subscribers/advertise

Neurology ${ }^{\circledR}$ is the official journal of the American Academy of Neurology. Published continuously since 1951 , it is now a weekly with 48 issues per year. Copyright @ 2016 American Academy of Neurology. All rights reserved. Print ISSN: 0028-3878. Online ISSN: 1526-632X.

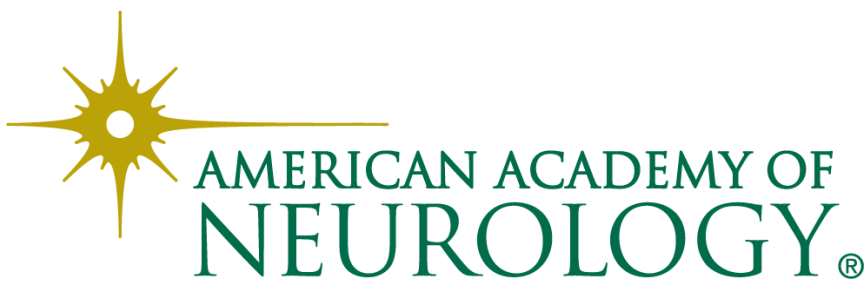

